Dos benefícios da depressão: elogio da psicoterapia Pierre Fédida São Paulo: Escuta, 2002

\title{
Um elogio à vida psíquica
}

\section{Débora Siqueira Bueno}

Uma sensação quase física de aniquilamento e imobilização, um impedimento dos movimentos da vida psíquica e da vida externa, abolição de qualquer devaneio ou desejo. A queixa é pobre, repetitiva, como um lamento afastado da percepção do sofrimento vivido, como uma voz que constata um processo de desaparecimento. Uma violência do vazio parece dominar o pensamento, a ação e a linguagem. No estado deprimido, é a própria aparência humana que se apaga. A depressão é apresentada como uma doença do humano, uma doença humana do tempo. Doença do humano retomando a idéia aristotélica de que a depressão é uma doença da forma, sendo o psiquismo aquilo que dá forma ao ser humano. Doença humana do tempo porque na depressão a temporalidade é perdida, atingindo a potencialidade para a ação, para a linguagem e para a comunicação com o outro. A paisagem glacial é a metáfora para descrever esta solidão absoluta e a aparente ausência de vida psíquica. Por outro lado, este modelo permite conceber o psíquico como capaz de conservação da vida, ao dispor de uma capacidade de proteção face ao traumático por meio da regressão. A depressão pode resguardar a vida psíquica, numa função de homeostase que não deveria ser subestimada. Adoecimento do psíquico, proteção do psíquico.

Nos seis primeiros capítulos do livro Dos benefícios da depressão - elogio da psicoterapia, de Pierre Fédida, a depressão é 
o tema central e eixo condutor da discussão. Uma das hipóteses clínicas apresentadas é de que, na maioria dos estados depressivos, o trabalho de análise encontra um forte recalcamento que se refere a uma morte desapercebida: uma perda que pode até ser admitida, mas que foi esquecida ou subestimada, ficando então despojada de suas conseqüências para a economia psíquica. Na depressão esta negligência pode transformar o sujeito na própria sepultura destes mortos esquecidos a que se recusou o pensar e o sonhar. A presunção depressiva é discutida como um dos movimentos defensivos na depressão, uma espécie de fuga para o alto, em função da angústia aterrorizante pela interiorização dos mortos. É encontrada na clínica como um devaneio onipotente, com tentativas desesperadas de resolução por meio de um discurso de ideal do eu. Seriam como que tentativas de reanimação de si mesmo, com risco de precipitação numa onipotência maníaca ou na melancolia.

O conceito de depressividade é apresentado no primeiro capítulo a partir de um paciente que na análise emergiu de um estado depressivo. O cuidado oferecido pelo analista permitiu torná-lo aos poucos um interlocutor, o que substituiu o solilóquio inicial do paciente. A capacidade de associar e de sonhar foi sendo retomada, em um reencontro com uma vida interior. Esta capacidade de contato consigo mesmo e de autonomia é chamada por Fédida de depressividade ou capacidade depressiva, referindo-se à constituição da experiência da perda e da transformação interna por ela. Este conceito relacionase à posição depressiva de Melanie Klein, ao jogo do fort-da de fazer desaparecer e reaparecer o objeto, e às idéias de Winnicott sobre a experiência psíquica de retraimento. Assim como de um estado depressivo pode-se resgatar a capacidade depressiva, esta pode ser perdida sob o efeito de fatores internos ou externos. Ao autor interessa compreender como o equilíbrio da vida psíquica plena de recursos pode ser rompido, impondo a lentificação do tempo e a massificação da vida psíquica próprias do estado depressivo. Para se chegar à capacidade depressiva é preciso contar com a elaboração a partir do fantasma.

O terceiro capítulo trata da depressividade do fantasma. O estudo da anamorfose por Lacan é tomado para apontar o privilégio que este autor dá ao fantasma em lugar do sintoma. Melanie Klein é lembrada por sua acentuação na função de objeto do analista na relação transferencial, colocando-o às voltas com os fantasmas inconscientes desde o início.

Neste percurso de abordagem do fantasma, o consultório de Berggasse 19 também é visitado. Um rico estudo arquitetônico é utilizado por Fédida para uma leitura dos lugares, permitindo retomar o vértice da condição depressiva do nascimento do fantasma. O consultório de Freud estaria organizado como um túmulo íntimo: a própria invenção da situação analítica concedeu um lugar à designação da morte. Fédida sustenta que é da relação com a morte do outro 
R E V I S

LATINOAMERICANA

DE PSICOPATOLOGIA

F U N D A M E T A L

ano $V$, n. 4, dez/ 2002

amado que procede a fantasmática da metáfora, e a capacidade depressiva precisa dessa vida fantasmática que se alimenta da ausência do objeto. Por evocar sempre o perdido, o fantasma apela à sua visualidade numa tentativa de restituição. A presença real do psicanalista e a regra de abstinência fazem dele o representante de uma realidade fantasmada. Fédida se detém sobre a transferência em sua capacidade de exercer a alucinação negativa, uma disposição psíquica para fazer desaparecer a pessoa do analista conservando ao mesmo tempo sua presença, sem a qual a fantasmática não seria possível. O autor aponta dois riscos: o de que a fantasmática se refugie na situação psicanalítica, numa cumplicidade entre a sessão de análise e o fantasma, delírio ou sonho no imaginário de transferência; e o da redução da comunicação entre analista e analisando a mera comunicação intersubjetiva, desfazendo a própria idéia de situação psicanalítica ao retirar desta sua dimensão fantasmática. A função do fantasma na construção da situação psicanalítica deve ser pensada de maneira que a escuta e a interpretação se realizem como uma atividade metapsicológica.

A idéia de uma psicoterapia psicanalítica encontra no paciente deprimido forte resistência. A desesperança e o excesso de ruminações apelam a uma recuperação sem vida psíquica: a psicoterapia pode ser colocada diante do paradoxo de curar o humano do psíquico que o faz sofrer. É preciso inicialmente atravessar o sentimento dissuasivo do paciente de que o contato não serve para nada, com sua fala restrita a um discurso de comentário proveniente de uma instância interna. Muitos riscos podem ser encontrados na psicoterapia de um paciente deprimido. O paciente pode querer aderir ao analista, con-fundir-se com a presença dele, buscando reencontrar um objeto vivo. O discurso interno lentificado funciona como salvaguarda contra uma precipitação na melancolia, mas uma autofascinação pelo processo de desaparecimento pode fazer configurar na análise uma situação simbólica de sacrifício pelo suicídio.

A depressão produz efeitos violentos sobre a vida psíquica do analista e desorganiza a situação analítica. Pode desencadear reações de angústia que comprometam a disponibilidade de linguagem do analista, ou produzam uma hiperatividade mental defensiva que leva a um excesso de representações e interpretações. $\mathrm{O}$ analista não deve compreender demais, pois isto o impede de escutar. Na depressão são exigidas do analista mobilidade psíquica vigilante e proximidade. Com sua presença silenciosa ele deve estar disponível para uma recepção singular dos afetos, e então formar em si impressões e imagens que tragam as palavras que os nomeiem. Para tanto, é preciso que o analista tenha uma percepção de sua própria membrana de ressonância. Seu enrijecimento implica num correspondente endurecimento e fechamento no paciente, interrompendo o movimento regressivo. O comportamento excessivamente neutro do analista pode fazer com que o paciente perca a esperança psíquica de uma 
troca que o faria “... entre-perceber na presença do outro tonalidades suscitadas por seu próprio desamparo”. Isto torna a comunicação ao paciente de afetos contratransferenciais do analista, desde que de forma comedida e oportuna, um caminho para a restituição de um ambiente humano. Nomeando o sétimo capítulo, é preciso ser dois para curar: a psicoterapia vai buscar a descoberta de uma vida psíquica/ vida do psíquico, compondo sessão a sessão “... um tecido de pensamento e de representação”, sob a proteção do setting, assegurado internamente pela presença do analista e garantido, por algum tempo, pelo vínculo de confiança com ele.

O paciente deprimido pede tempo, e negligenciar esta necessidade o privaria da possibilidade de redescobrir, através da fala, sua própria modulação do tempo. Nos casos de depressão a experiência clínica mostra a importância decisiva da regularidade e duração das sessões, por esta relação direta com a problemática intersubjetiva do tempo. O analista deve com prudência evitar a produção no paciente de uma aceleração do tempo que leve a actings de melhora ou cura: curas rápidas demais submetem o indivíduo a falsas adaptações. É preciso, então, considerar um tempo de não mudança, em que o trabalho analítico prossiga remanejando material psíquico no decorrer da regressão transferencial, sem a normatividade de um progresso em direção à cura. É preciso sustentar que nada aconteça numa psicanálise. É a depressividade do próprio analista, com sua própria percepção de um ritmo interno que regula seu pensamento, que evitaria uma saída excessivamente rápida do estado deprimido. Se o tratamento psicanalítico é regulado pelos paradigmas do sonho e da transferência, ele permite cuidar para que nada aconteça. O tratamento deve restituir uma depressividade a partir da fala, deixando que o psíquico se reaproprie de sua própria temporalidade.

Neste cenário se impõe a preocupação com as questões trazidas pela psicofarmacoterapia atual. Em um "neopragmatismo" do tratamento do psíquico pelo químico, o fármaco passou a ter o poder de produzir um bem-estar com a aparência de um estado tímico natural sem passar pelo levantamento de um recalque. O autor busca a leitura feita por Derrida do Fedra, de Platão, para trabalhar o conceito de pharmakon. A operação platônica consiste na desqualificação do pharmakon como substância, e sua requalificação pela fala formada do interior. A arte terapêutica estaria em acolher a própria necessidade da doença, só fazendo intervir a substância farmacêutica em estreita aliança com a fala, que pode assim reconhecer a substância e interiorizar sua ação. Se o pharmakon simplesmente vier de fora, não só não terá uma virtude própria como também acrescentará sua patogenia. A psicoterapia da depressão pode contribuir pela compreensão de como uma substância química se qualifica ou não como medicamento num processo de tratamento. A ética deve se contrapor ao positivismo terapêutico ao exigir dos psicofármacos sua qualificação clínica 
R E V I S T A

LATINOAMERICANA

DE PSICOPATOLOGIA

F U N D A M E T A L

ano $V$, n. 4, dez/ 2002

através de uma fala em transferência. A própria eficácia de um fármaco depende de sua metaforização subjetiva.

Nesta conjuntura sem precedentes, em que a neurofarmacologia se considera tanto mais científica quanto mais emancipada da psicopatologia, a busca de um estatuto científico para a psicoterapia vem colocar em questão a manutenção do paradigma freudiano. $\mathrm{O}$ abandono ou relativização de concepções como o funcionamento psíquico, a função do sintoma, do sonho e da transferência, o lugar da sexualidade infantil e a teoria das pulsões afetariam toda a base da metapsicologia. Uma singularidade desta questão reside na insistência em avaliar a eficácia terapêutica por meio de critérios quantitativos, beneficiando as práticas psicoterápicas assentadas no tratamento e cura do sintoma. Evidentemente a psicoterapia psicanalítica inserida no modelo da psicanálise freudiana teria dificuldades neste tipo de comparação, correndo o risco de ser relegada a um estatuto de prática humanista mais ou menos obscura. Com certo desolamento, o autor constata no próprio movimento psicanalítico contemporâneo o incentivo a uma aproximação ao modelo das neurociências, como se elas fossem renovar os fundamentos da teoria freudiana ou mesmo eximir a psicanálise das condições expressas por Freud para seu reconhecimento e legitimação. O resultado é uma reivindicação pragmática de eficácia terapêutica do tratamento do sintoma. Fédida remete-se a Charcot, para quem a cura do sintoma e o milagre teriam a mesma estrutura e gênese de produção. A questão da cura deve comportar um paradoxo: não se pode negar à psicoterapia ou à psicanálise a possibilidade de curar, mas o analista não pode pretender produzir as causalidades psíquicas que levam à cura do sintoma. Quando se trata da vida psíquica, cura é uma noção inadequada. Para o autor não se pode ver com bons olhos a aplicação de critérios de avaliação que visem verificar a eficiência de resultados do processo psicoterapêutico. Uma recusa categórica a qualquer avaliação de resultados deve ser sustentada.

É diante do cenário dado por este contexto sociocultural que Fédida toma o partido de que não se pode conceber uma prática psicoterápica que não seja psicanalítica. Ciente do caráter radical desta afirmação, e lembrando que a psicoterapia é parte integrante da psicanálise, o que interessa ao autor é ressaltar a necessidade de se conceber a psicoterapia como uma análise complicada, convocando os psicanalistas e as instituições psicanalíticas a considerarem plenamente esta complicação, tanto técnica quanto teoricamente. No modelo freudiano o analista se torna analista do paciente quando este se abandona a uma fala em livre associação. Já na psicoterapia, a pessoa do analista é solicitada a tornar-se um terceiro imaginário, permanecendo analista. O tornar-se analista nunca está garantido de uma vez por todas. A situação analítica se desinstala e deve ser reinstalada, permanecendo como uma ficção ideal que o analista não pode dispensar. Fédida faz um enfático elogio à psicoterapia - uma prática de 
grande valor, justamente por revelar uma extraordinária riqueza técnica e metapsicológica. Não se justifica a definição da psicoterapia como uma análise menor, nem sua distinção da psicanálise clássica usando-se apenas o critério formal do enquadre. Na verdade, a psicoterapia é um tratamento que apresenta extrema dificuldade. “A psicoterapia na psicanálise hoje”: ao longo de sua argumentação o autor fez questão de sair da exclusiva referência ao sintoma, o que algumas vezes regula a definição de uma psicoterapia. Ele sustenta que “... a psicoterapia não é somente parte integrante da psicanálise, mas constitui realmente sua atividade mais investida em razão das organizações e funcionamentos arcaicos com os quais lida”. Atualmente, é a riqueza clínica da psicoterapia que tem contribuído para avançar na compreensão e tratamento do psiquismo humano.

Fenômeno, e não sintoma. Na depressão a fenomenologia remete a modificações do "ser-no-mundo", não redutíveis aos sintomas. Embora o modelo metapsicológico da melancolia continue sendo prevalente quando se trata de pensar a depressão em sua relação com o luto e a perda de objeto, outros aspectos da relação entre o estado deprimido e a depressividade do psíquico podem ser investigados. O interesse da psicanálise não está simplesmente nas formações sintomáticas, está também na contribuição para uma teoria metapsicológica do psíquico dada pela depressividade. A clínica da depressão pode impor um movimento de retorno do pensamento psiquiátrico às suas bases na fenomenologia e na psicopatologia. Neste movimento de reversão a depressão não teria o estatuto de uma doença, mas de um proto-afeto, e o grande interesse no trabalho clínico e teórico seria o de elaborar uma teoria do afeto de depressão. Herdeira de uma tradição filosófica e médica muito prestigiada e considerada fundamento da psiquiatria clínica, a psicopatologia pode hoje parecer inútil diante da generalização de noções como a depressão e da prática psiquiátrica pragmática de prescrição. Para Fédida, este cenário não deve suscitar temores, mas sim solicitar que se coloque à prova as referências e os contextos de reflexão deste saber. A psicopatologia não deve ser convocada para um mero retorno à semiologia médica e à nosografia. É o tratamento - psico e farmacoterápico que “... exige a redefinição de um campo onde objetos e modelos diversamente elaborados são colocados em situação de confronto crítico”. Fédida defende a constituição de uma psicopatologia fundamental nas intersecções teóricas onde se decidem novos objetos, no que deve muito à clínica psicoterápica. Reconhecer a importância da psicopatologia não deveria ser resultado de um exercício retórico, nem se constituir no retorno a um saber médico positivo no qual o diagnóstico é um indicador terapêutico. "A reavaliação da função da psicopatologia está aqui relacionada com a escolha que se impõe de início de uma psicoterapia. E é esta última que pode modificar o estatuto que convém, a partir de agora, conferir ao que chamamos de psicopatologia”. 


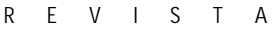

LATINOAMERICANA

DE PSICOPATOLOGIA

F U N D A M E T A L

ano V, n. 4, dez/ 2002

O estado deprimido revela em negativo a vida psíquica. A psicoterapia psicanalítica constitui exatamente a possibilidade de reanimação da vida psíquica, ao restituir ao sujeito sua capacidade depressiva e sua criatividade psíquica. Este é um livro sobre a psicoterapia da depressão (...) e o tempo de escrever este livro é o tempo (...) de lembrar que, quando trata da vida psíquica do humano, não se pode poupar tempo para escutar.

O tempo deste livro parece ser também o tempo de maturação de uma vida. Vários temas desenvolvidos anteriormente pelo autor são retomados, como a situação analítica, o lugar do analista como estrangeiro, a compreensão da psicopatologia como conceito psicanalítico. Nos casos clínicos apresentados pode-se vislumbrar uma escuta extremamente refinada. A discussão desenvolvida a propósito da depressão traz também fecundas contribuições para a clínica da neurose obsessiva, da hipocondria, dos fenômenos de adição e dos estados-limite. Autores provenientes da fenomenologia, filosofia, história, arte e literatura participam como interlocutores. Freud é uma referência constante. Lacan, Pontalis, Laplanche, Lagache e outros assinalam com sua presença a importante influência da escola francesa no pensamento do autor. Há uma congruência estreita com Ferenczi e Balint principalmente quanto à clínica do traumático, e uma aproximação com as questões da técnica ativa. Mas é com a tradição independente britânica, representada sobretudo por Winnicott, que o pensamento de Fédida parece encontrar uma maior afinidade. Uma correlação com o conceito bioniano de capacidade negativa seria pertinente, mas não chega a ser sugerida pelo autor. Esta resenha não tem como contemplar todos os pontos importantes deste livro, pois certas preciosidades só podem ser encontradas através da ressonância que o texto produz no leitor. Apenas para citar uma delas, num desdobramento da teoria de Winnicott sobre o papel de espelho do olhar da mãe para se pensar a morte, o autor supõe uma morte suave como a possibilidade de ver o próprio rosto refletido nos olhos daquele cuja angústia o conserva. 